\title{
DESEMPENHO DA GLIRICÍDIA NO CULTIVO EM ALEIAS EM POMAR ORGÂNICO DE MANGUEIRA E GRAVIOLEIRA ${ }^{1}$
}

\author{
Gleicia Miranda Paulino², Deborah Guerra Barroso ${ }^{3}$, Kelly Ribeiro Lamônica ${ }^{3}$, Gilmar Santos Costa $^{4}$ e \\ José Geraldo de Araújo Carneiro ${ }^{3}$
}

\begin{abstract}
RESUMO - Foi estabelecido um sistema de cultivo em aléias de gliricídia em um pomar orgânico de mangueira e de gravioleira de um ano, no município de Campos dos Goytacazes-RJ-Brasil. Os objetivos do trabalho foram avaliar a sobrevivência e o desempenho da gliricídia no cultivo em aléias, quanto à produção de fitomassa seca e ao fornecimento de nutrientes ao sistema. A gliricídia apresentou elevada sobrevivência (93\%). A média anual de produção de fitomassa seca e de adição de nutrientes ao sistema foi maior no segundo ano de avaliação (2007) do que no primeiro ano (2006), ambos com de três podas anuais que se adequaram às épocas recomendadas para a adubação das frutíferas, especialmente a gravioleira. A quantidade de $\mathrm{N}$ adicionada ao pomar com as podas da gliricídia foi maior que a adubação recomendada para mangueira e gravioleira. Por outro lado, a quantidade de P e K adicionada ao pomar não foi suficiente para suprir a adubação demandada para ambas as culturas. A gliricídia apresentou bom desempenho nas condições do experimento, com potencial de uso contínuo no sistema e possibilidade de aproveitamento dos nutrientes disponibilizados no sistema pelas frutíferas. Contudo, mais avaliações são necessárias ao longo do tempo para verificar a sustentabilidade do consórcio.
\end{abstract}

Palavras-chave: Adubação verde, Gliricidia sepium e Cultivo em Aléias.

\section{PERFORMANCE OF GLIRICIDIA IN ALLEY CROPPING IN AN ORGANIC ORCHARD OF MANGO AND SOURSOP}

\begin{abstract}
An alley cropping system with gliricidia was established in an organic orchard of mango and soursop trees at one year after the planting of the fruit trees, in Campos dos Goytacazes-RJ-Brazil. The objective of this work was to evaluate the survival and performance of the gliricidia in the alley cropping in relation to the production of dry fitomass and the nutrient supply to the system. Gliricidia showed high survival rates (93\%). The annual average of dry fitomass yield and the addition of nutrients to the system were greater in the second year of evaluation (2007) than in the first year (2006), both with three annual prunings that adjusted with the recommended periods of fruit trees fertilization, in special the soursop tree. The quantity of $N$ added to the orchard with gliricidia prunes was higher than the recommended fertilization for mango and soursop tree plots. On the other hand, quantities of $P$ and K added to the orchard were not enough to supply the fertilization demanded for both cultures. Gliricidia presented good performance under the experiment conditions, with potential for continuous use in the system and possibility of using nutrients supplied by the fruit trees into the system. However, further long term evaluations are necessary to verify the sustainability of the intercropping.
\end{abstract}

Keywords: Alley Cropping system, Gliricidia sepium and Green manure.

\footnotetext{
${ }^{1}$ Recebido em 14.07.2008 e aceito para publicação em 20.04.2011.

${ }^{2}$ Departamento de Recursos Naturais, Ciências e Tecnologias Ambientais, Universidade Estadual de Minas Gerais, UEMG/ FaEnge, João Monlevade-MG, Brasil. E-mail < gleiciamiranda@yahoo.com.br>

${ }^{3}$ Universidade Estadual do Norte Fluminense - Darcy Ribeiro, UENF, Campos dos Goytacazes-RJ, Brasil. E-mail: <deborah@uenf.br>, <krlamonica@gmail.com>e < carneiro@uenf.br>.

${ }^{4}$ Instituto Federal Fluminense, IFF, Campos dos Goytacazes-RJ, Brasil. E-mail: <gilmariff@gmail.com>.
} 


\section{INTRODUÇÃO}

O cultivo em aleias é um modelo de sistema agroflorestal que consiste no estabelecimento de espécies arbóreas ou arbustivas em fileiras espaçadas o suficiente entre si, permitindo o cultivo de outras culturas agrícolas entre as fileiras das árvores (KANG, 1997). O manejo de podas periódicas das árvores ou arbustos resulta na adubação verde, cuja prática pode propiciar vantagens, como a recuperação ou melhoria da atividade biológica do solo e da ciclagem de nutrientes no agrossistema.

A gliricídia tem apresentando grande potencial para uso no cultivo em aleias por ser uma leguminosa arbórea de uso múltiplo, com alta produção de fitomassa e com boa adaptação a diferentes zonas ecológicas (KANG 1997; BARRETO et al., 2004). Porém, informações relacionadas a consórcio entre frutíferas e espécies usadas como adubo verde, principalmente de porte arbóreo, para regiões específicas, são ainda bastante escassas na literatura, sendo importante a realização de estudos regionalizados, visando a avaliar o desempenho e o comportamento das espécies e suas interações.

Ferraz Júnior (2002), ao analisar diversos trabalhos sobre sistema de cultivos em aleias, verificou que a adição ao solo de fitomassa seca proveniente de poda de ramos de diferentes leguminosas variaram de 1,4 a $8 \mathrm{t} \mathrm{ha}^{-1} \mathrm{ano}^{-1}$, e a fitomassa seca da gliricídia situa-se em torno de $5 \mathrm{t} \mathrm{ha}^{-1} \mathrm{ano}^{-1}$. Segundo o autor, as quantidades de nutrientes nos ramos das leguminosas, nesse sistema de cultivo, variam em função de diferentes fatores, como: a espécie de leguminosa, o tipo de solo, a intensidade de cortes dos ramos e as adubações realizadas.

Corrêa et al. (2006) relataram que a gliricídia consorciada com cacaueiros é uma opção para o sombreamento desta cultura. Além do efeito de sombra, ela proporciona, no Município de Ouro Preto do Oeste, RO, boa produção de fitomassa, depositando naturalmente no solo 3,43 $\mathrm{t} \mathrm{ha}^{-1} \mathrm{ano}^{-1}$.

O estudo teve como objetivo avaliar o desempenho da gliricídia no cultivo em aleias, em um pomar orgânico de mangueira e de gravioleira, no Município de Campos dos Goytacazes-RJ, quanto à sobrevivência, à produção de fitomassa seca e ao fornecimento de nutrientes para o sistema.

\section{MATERIAL E MÉTODOS}

Foi avaliado um plantio em aleias de gliricídia, estabelecido em um pomar orgânico de mangueira e gravioleira. Para isto, foi delimitada uma área de $4.608 \mathrm{~m}^{2}$ do pomar para a implantação das aleias. As mudas produzidas a partir de estacas, com cerca de $60 \mathrm{~cm}$ de comprimento e diâmetro variando entre 2,5 e 4,5 cm, foram plantadas em novembro de 2004, um ano após o estabelecimento do pomar. O plantio foi feito em covas de 40x40x40 cm, que receberam 51 de composto orgânico de casca de eucalipto e farinha de carne e ossos, a $2 \mathrm{~m}$ das linhas das frutíferas e no espaçamento de 4 x 4 m entre plantas de gliricídia. Cada frutífera foi circundada por quatro plantas de gliricídia, cuja finalidade foi a adubação verde das frutíferas através de podas periódicas das gliricídias.

O solo utilizado é Argissolo Amarelo, de textura arenoargilosa, com relevo plano, característico dos solos de tabuleiros (COSTA et al., 2004a). Este tipo de solo apresenta naturalmente horizonte subsuperficial coeso e adensado. O clima da região é do tipo Aw, pela classificação de Köppen, de temperaturas elevadas, e regime pluviométrico com estação chuvosa no verão e estiagem no inverno. As médias anuais de precipitação pluviométrica variaram entre 900 e 1.300 mm (entre 2005 e 2007), com maior ocorrência de chuvas nos meses de janeiro e fevereiro. A temperatura média anual foi de $23^{\circ} \mathrm{C}$, com máxima de $30^{\circ} \mathrm{C}$, conforme dados fornecidos pala Estação Experimental de Campos EEC PESAGRO - Campos dos Goytacazes, RJ. As coordenadas geográficas são: latitude de $21^{0} 36^{\prime} 49,6^{\prime \prime}$ S e longitude $41^{0} 16^{\prime} 25,7^{\prime \prime}$ W.

Um mês após o estabelecimento do pomar, o solo apresentava as seguintes características químicas de fertilidade, na profundidade de $0-20 \mathrm{~cm}: \mathrm{pH}=6,3$; $\mathrm{C}=10,2 \mathrm{~g} \mathrm{dm}^{-3} ; \mathrm{P}=10 \mathrm{~g} \mathrm{dm}^{-3} ; \mathrm{K}=0,5 \mathrm{~g} \mathrm{dm}^{-3} ; \mathrm{Ca}=17 \mathrm{mmol}_{\mathrm{c}}$ $\mathrm{dm}^{-3}$; $\mathrm{Mg}=7 \mathrm{mmol}_{\mathrm{c}} \mathrm{dm}^{-3} ; \mathrm{SB}=24 \mathrm{mmol}_{\mathrm{c}} \mathrm{dm}^{-3} ; \mathrm{CTC}=49 \mathrm{mmol}_{\mathrm{c}}$ $\mathrm{dm}^{-3} ; \mathrm{V}=50 \%$, avaliados conforme Embrapa (1997) por Costa et al., (2004a).

A área do sistema foi subdividida em nove unidades amostrais de $512 \mathrm{~m}^{2}$ cada uma, das quais seis foram selecionadas ao acaso, onde foram realizadas as amostragens e avaliações em diferentes períodos. $\mathrm{O}$ tamanho da amostra foi representativo do sistema em cada situação avaliada. Cada unidade amostral continha quatro mangueiras, quatro gravioleiras e 32 plantas de gliricídia. 
A sobrevivência da gliricídia foi avaliada seis meses após o plantio, em todas as seis unidades amostrais.

As gliricídias foram submetidas a sete podas, realizadas entre junho de 2005 e novembro de 2007, sendo o procedimento adotado sempre que as plantas atingiam uma altura de 2,15 m aproximadamente. A altura de corte foi de $1 \mathrm{~m}$ aproximadamente, e o material podado foi distribuído em torno da área sob a copa das frutíferas. Em todas as podas, quantificou-se a fitomassa podada, em cada planta, nas seis unidades amostrais. A parte aérea podada foi separada em folhas e ramos tenros (diâmetro d” 0,9 cm), e ramos lignificados (diâmetro $>0,9 \mathrm{~cm}$ ), que foram pesados para a estimativa da fitomassa fresca. Retiraram-se seis amostras de cada componente podado, que foram pesadas no campo e levadas à estufa de circulação forçada a $65^{\circ} \mathrm{C}$, por $72 \mathrm{~h}$. Após secagem, o material foi pesado para a estimativa da fitomassa seca.

Em três podas (segunda, quarta e sétima), porções das amostras já secas e moídas foram submetidas às digestões sulfúrica e nitro-perclórica (MALAVOLTA et al., 1997); os extratos utilizados para a determinação dos teores de Ca e Mg, por espectrofotometria de absorção atômica; S por turbidimetria de sulfatos, após digestão nitro-perclórica, P pelo método da vitamina C (BRAGA; DEFELIPO, 1974), e o K, por espectrofotometria de chama, após digestão sulfúrica. $\mathrm{N}$ total, determinado pela digestão Kjeldahl e $\mathrm{C}$ total por oxidação com $\mathrm{K}_{2} \mathrm{Cr}_{2} \mathrm{O}_{7}$ em meio ácido (ANDERSON; INGRAM, 1996).
O teor nutricional dos resíduos considerado no trabalho foi obtido pela média dos resíduos das três podas, que foram submetidas à análise $(n=18)$. A quantidade de nutriente contida nos resíduos que foi adicionada ao sistema, em cada poda, foi calculada pelo produto da fitomassa seca com o teor médio dos nutrientes.

A análise dos dados de produção de fitomassa, teor e acúmulo de nutrientes nos resíduos foi realizada com base no estabelecimento de intervalos de confiança para comparação das médias (COCHRAN, 1955), considerando-se o nível de significância de 5\%, e admitindo-se uma amostragem representativa de uma população infinita.

\section{RESULTADOS E DISCUSSÃO}

A sobrevivência da gliricídia foi de 93\%, o que mostra o bom estabelecimento das mudas, em estaca, no campo quando as condições climáticas apresentam precipitação e temperaturas mais elevadas, como mostra a Figura 1. O plantio, realizado no fim de novembro de 2004, foi favorecido com o início do período chuvoso, que perdurou até janeiro de 2005. Além disso, a espécie tem como característica boa resistência à restrição hídrica, favorecendo seu estabelecimento no campo (BARRETO et al., 2004). Entretanto, na mesma região deste trabalho, Costa et al. (2004b) obtiveram um porcentual de sobrevivência da gliricídia, propagadas por estacas,

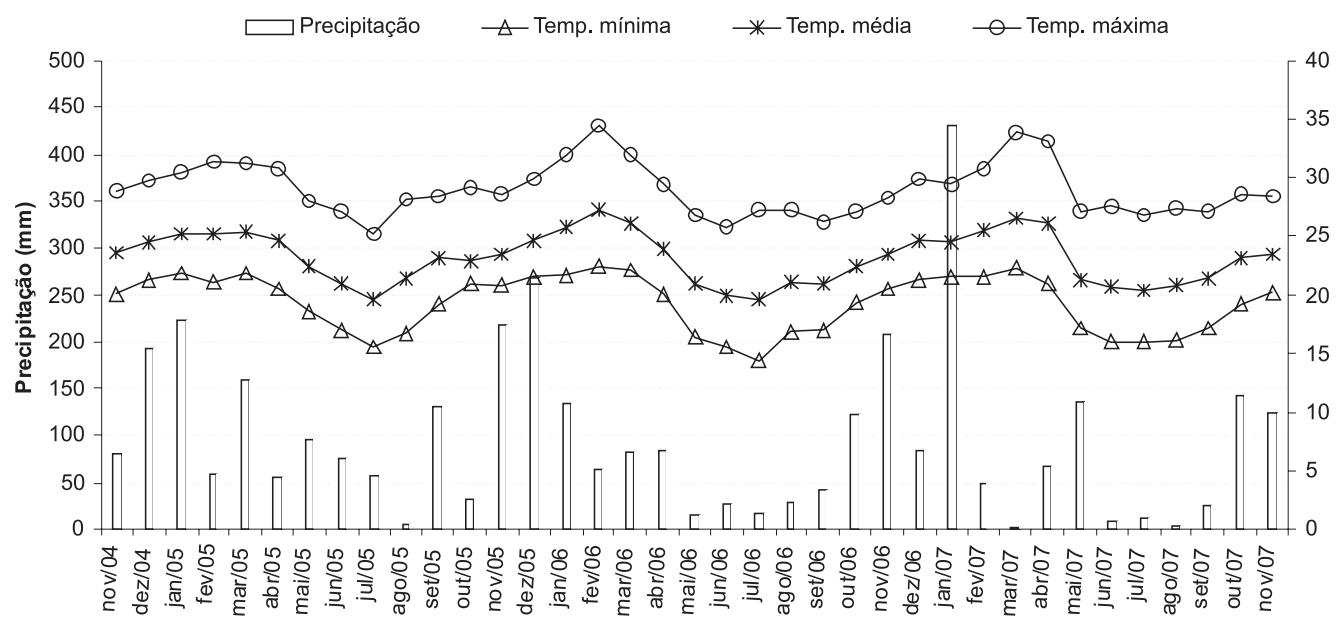

Figura 1 - Precipitação pluvial acumulada no mês (mm), temperaturas máxima, mínima e média mensal $\left({ }^{\circ} \mathrm{C}\right)$, em Campos dos Goytacazes-RJ.

Figure 1 - Pluvial precipitation accumulated in the month $(\mathrm{mm})$, maximum, low and average monthly temperatures $\left({ }^{\circ} \mathrm{C}\right)$, in Campos dos Goytacazes-RJ (Brazil). 
de $70 \%$, o que associaram ao prolongado período com poucas chuvas e altas temperaturas após o plantio, feito em janeiro de 2003.

A produção de fitomassa diferiu entre as podas (Tabela 1), destacando-se a quinta poda com maior quantidade de material. Isto está relacionado às chuvas elevadas que ocorreram no fim de 2006 e janeiro de 2007 (Figura 1), favorecendo a rebrota e o crescimento das plantas.

A primeira poda da gliricídia aos 6,5 meses após o plantio resultou em baixa produção de fitomassa (Tabela 1) e, consequentemente, em baixa adição de nutrientes ao sistema, devido ao curto intervalo de tempo para o crescimento das plantas. Porém, esta poda permitiu melhor uniformidade do estande para as posteriores avaliações.

Nas demais podas, foram obtidas elevadas quantidades de fitomassa seca (Tabela 1). As maiores produções de fitomassa seca obtidas nos meses de novembro e janeiro podem estar relacionadas com as variáveis climáticas, uma vez que coincidiram com o período de maiores precipitações pluviométricas e temperaturas da região (Figura 1). Isto favoreceu a rebrota e o crescimento das plantas e refletiu no regime de podas, que ficou concentrado no período chuvoso. Pode-se observar que, na quinta poda, seguida pela quarta, foram obtidas as maiores produções de fitomassa em relação às demais. A explicação para isso é o período de elevadas precipitações entre novembro de 2006 e janeiro de 2007.

A quantidade de fitomassa proveniente de ramos tenros e folhas foram maiores do que a fitomassa de ramos lignificados, em uma proporção média de $60 \%$ e $40 \%$, respectivamente. A relação ramo tenro/ramo lignificado é importante, pois o primeiro, geralmente, apresenta teores mais elevados de nutrientes e é de mais fácil decomposição em relação ao segundo. Isso resulta na disponibilização de grande quantidade de nutrientes de forma mais rápida. Por outro lado, os ramos lignificados, que são de lenta decomposição e liberam mais lentamente os nutrientes, podem contribuir para elevar o conteúdo de carbono orgânico no solo e na proteção superficial.

A espécie mostrou-se vigorosa, com elevado potencial de rebrota, apresentando excelente desempenho para integrar cultivos em aleias e para adubação verde. Estes resultados estão de acordo com os estudos de Barreto et al. (2004), que relataram que a gliricídia tem demonstrado grande adaptabilidade a regiões de solos de tabuleiros costeiros, apresentando desenvolvimento vegetativo vigoroso, sem problemas fitossanitários e com alta capacidade de melhorar a fertilidade do solo.

Tabela 1 - Produção de fitomassa seca de gliricídia, consorciada com frutíferas, sob um regime de 7 podas, em Campos dos Goytacazes-RJ.

Table 1 - Dry fitomass production of gliricidia associated with fruit trees in seven prunings in Campos dos Goytacazes$R J$.

\begin{tabular}{|c|c|c|c|c|c|}
\hline \multirow[t]{2}{*}{$\overline{\text { Poda }}$} & \multirow[t]{2}{*}{ Época de poda * } & \multicolumn{3}{|c|}{ Dry fitomass } & \multirow[b]{2}{*}{$\begin{array}{l}\text { Relação } \\
\text { RT/RL** }\end{array}$} \\
\hline & & $\begin{array}{l}\text { Ramos tenros } \\
\text { e folhas }\end{array}$ & $\begin{array}{c}\text { Ramos } \\
\text { lignificados } \\
\mathrm{kg} \mathrm{ha}^{-1}\end{array}$ & Total & \\
\hline 1 & $06 / 2005$ & $47 \pm 8,0$ e & $29 \pm 4,0 \mathrm{~d}$ & 76 & 1,62 \\
\hline 2 & $01 / 2006$ & $416 \pm 27 \mathrm{~d}$ & $306 \pm 50$ c & 722 & 1,36 \\
\hline 3 & $03 / 2006$ & $377 \pm 46 \mathrm{~d}$ & $293 \pm 38 c$ & 670 & 1,29 \\
\hline 4 & $11 / 2006$ & $624 \pm 61 \mathrm{~b}$ & $420 \pm 60 \mathrm{~b}$ & 1044 & 1,48 \\
\hline Total em $2006\left(\mathrm{~kg} \mathrm{ha}^{-1} \mathrm{ano}^{-1}\right)$ & 1417,0 & 1019,0 & 2436,0 & & \\
\hline 5 & $01 / 2007$ & $1092 \pm 159$ a & $634 \pm 127$ a & 1726 & 1,72 \\
\hline 6 & $4 / 2007$ & $469 \pm 86$ cd & $308 \pm 30$ c & 777 & 1,52 \\
\hline 7 & $11 / 2007$ & $497 \pm 70$ bc & $389 \pm 48$ bc & 886 & 1,28 \\
\hline Total em $2007\left(\mathrm{~kg} \mathrm{ha}^{-1} \mathrm{ano}^{-1}\right)$ & 2058,0 & 1331,0 & 3389,0 & & \\
\hline
\end{tabular}

Revista Árvore, Viçosa-MG, v.35, n.4, p.781-789, 2011 
O crescimento e o desenvolvimento da gliricídia permitiram um regime de três podas anuais (Tabela 1). De acordo com Barreto et al. (2004), geralmente em torno de quatro meses após algum corte, as plantas de gliricídia recompõem toda parte aérea, possibilitando a realização de três por ano, proporcionando uma produção média de 4,5 t ha $^{-1}$ ano $^{-1}$ de fitomassa seca, provenientes de folhas e ramos com diâmetro menor que $1 \mathrm{~cm}$.

A produção anual de fitomassa seca da gliricídia em 2006 (Tabela 1), de $2.436 \mathrm{~kg} \mathrm{ha}^{-1} \mathrm{ano}^{-1}$, foi semelhante à obtida por Mafra et al. (1998), em aleias de leucena, que foi de $2.398 \mathrm{~kg} \mathrm{ha}^{-1}$ ano $^{-1}$. Em 2007, a produção de fitomassa seca foi superior, resultando em 3.389 $\mathrm{kg} \mathrm{ha}^{-1} \mathrm{ano}^{-1}$. Isto corresponde a um aumento em torno de $40 \%$. Esses resultados sugerem bom estabelecimento da espécie na área.

Queiroz et al. (2007), trabalhando na mesma região em que foi realizado este trabalho, avaliaram por dois anos a produtividade de fitomassa seca da parte aérea (ramos < que 1,5 cm de diâmetro) da gliricídia em aleias, no espaçamento de 5,6 $\times 0,5 \mathrm{~m}$, submetidas a duas podas por ano, e o efeito da adubação fosfatada sobre a leguminosa. No primeiro ano, a produtividade foi de $360 \mathrm{~kg} \mathrm{ha}^{-1}$ e de $528 \mathrm{~kg} \mathrm{ha}^{-1}$, sem e com a adubação fosfatada, respectivamente. Já no segundo ano, a produtividade foi de $2.386 \mathrm{~kg} \mathrm{ha}^{-1}$ e de $2.856 \mathrm{~kg} \mathrm{ha}^{-1}$, sem e com adubação, respectivamente, semelhante à obtida neste trabalho em 2006 (2.436 kg ha-1) e inferior à produção de 2007 (3.389 kg ha-1), mesmo usando maior densidade de plantas.

Comparando-se a produção anual de fitomassa seca obtida neste trabalho com aquela apresentada por Queiroz et al. (2007), pode-se inferir que, nas condições edáficas do local onde foi realizado este trabalho, houve efeito da adubação orgânica realizada no plantio da gliricídia, favorecendo o estabelecimento das plantas na área e sua capacidade de acumular fitomassa e nutrientes.

Em relação à composição química dos resíduos vegetais da parte aérea da gliricídia, foi observado que a espécie produz um adubo verde de boa qualidade, podendo acumular boa quantidade de nutrientes de baixa relação $\mathrm{C}: \mathrm{N}$, especialmente nas partes mais tenras ou menos lignificadas (Tabela 2).

Os teores médios de nutrientes obtidos neste trabalho são superiores aos obtidos por Barreto e Fernandes (2001), com exceções para o K e o S. Estes autores relataram teores de N, P, K, Ca, Mg e S em ramos de gliricídia com diâmetro menores que $1 \mathrm{~cm}$ de: 27,$3 ; 1,7 ; 15,6 ; 10,7 ; 6,6$ e $2,9 \mathrm{~g} \mathrm{~kg}^{-1}$, respectivamente. Por outro lado, Queiroz et al. (2007) obtiveram teores médios de N, P, K na fitomassa seca da parte aérea de gliricídia (com ramos grossos descartados) de 31,4; 1,7 e $12 \mathrm{~g} \mathrm{~kg}^{-1}$, respectivamente.

Silva et al. (2006), avaliando folhas de gliricídia em um sistema agroflorestal em Seropédica/RJ obtiveram 426,9 g kg $^{-1}$ de C, 3,85 g kg$^{-1}$ de $\mathrm{N}$ e 11,9 de relação $\mathrm{C}: \mathrm{N}$. O teor de $\mathrm{C}$ obtido nos ramos tenros e nas folhas deste trabalho foi semelhante ao obtido por Silva et al. (2006), enquanto o teor de $\mathrm{N}$ foi inferior, o que resultou em maior relação C:N.

A poda das gliricídias em 2005 resultou em baixa adição de nutrientes ao sistema (Tabela 3), devido à menor produção de fitomassa (Tabela 1). Observa-se que houve aumento na adição média de nutrientes e de carbono ao solo entre 2006 e 2007 (Tabela 3).

Tabela 2 - Teores de nutrientes e relação C/N da fitomassa seca da gliricídia consorciada com frutíferas e relação C/N, em Campos dos Goytacazes-RJ.

Table 2 - Nutrient contents and C/N ratio in the dry fitomass of gliricidia associated with fruit trees, in Campos dos Goytacazes-RJ.

\begin{tabular}{lcc}
\hline Nutrientes & Ramos tenros e folhas & Ramos lignificados \\
\hline $\mathrm{N}\left(\mathrm{g} \mathrm{kg}^{-1}\right)$ & $31,47 \pm 2,82$ & $11,76 \pm 0,07$ \\
$\mathrm{P}\left(\mathrm{g} \mathrm{kg}^{-1}\right)$ & $2,43 \pm 0,17$ & $0,90 \pm 0,07$ \\
$\mathrm{~K}\left(\mathrm{~g} \mathrm{~kg}^{-1}\right)$ & $14,87 \pm 1,47$ & $5,55 \pm 0,81$ \\
$\mathrm{Ca}\left(\mathrm{g} \mathrm{kg}^{-1}\right)$ & $8,90 \pm 0,86$ & $2,80 \pm 0,26$ \\
$\mathrm{Mg}\left(\mathrm{g} \mathrm{kg}^{-1}\right)$ & $4,48 \pm 0,38$ & $1,32 \pm 0,12$ \\
$\mathrm{~S}\left(\mathrm{~g} \mathrm{~kg}^{-1}\right)$ & $1,93 \pm 0,12$ & $1,44 \pm 0,09$ \\
$\mathrm{C}\left(\mathrm{g} \mathrm{kg}^{-1}\right)$ & $422,5 \pm 2,61$ & $430,5 \pm 3,10$ \\
$\mathrm{C} / \mathrm{N}$ & $13,22 \pm 0,92$ & $42,50 \pm 3,24$ \\
\hline
\end{tabular}

Intervalo de confiança para média, a 95\% $(\mathrm{n}=18)$ 
Tabela 3 - Nutrientes adicionados ao sistema nas diversas podas da parte aérea da gliricídia no sistema de aléias, em um pomar orgânico de mangueira e gravioleira, em Campos dos Goytacazes-RJ.

Table 3 - Nutrients added to the system in the several prunings of the gliricidia aerial section in the alley cropping system, in an organic orchard of mango and soursop trees in Campos dos Goytacazes-RJ.

\begin{tabular}{|c|c|c|c|c|c|c|c|c|}
\hline \multirow[t]{2}{*}{ Poda } & \multirow[t]{2}{*}{ Componente } & \multicolumn{7}{|c|}{ Nutriente $\left(\mathrm{kg} \mathrm{ha}^{-1}\right)$} \\
\hline & & $\mathrm{N}$ & $\mathrm{P}$ & $\bar{K}$ & $\mathrm{Ca}$ & $\mathrm{Mg}$ & $\mathrm{S}$ & $\overline{\mathrm{C}}$ \\
\hline \multirow[t]{2}{*}{1} & A* & $1,48 \pm 0,25$ & $0,11 \pm 0,02$ & $0,70 \pm 0,12$ & $0,42 \pm 0,07$ & $0,21 \pm 0,04$ & $0,09 \pm 0,02$ & $19,86 \pm 3,38$ \\
\hline & $\mathrm{B} * *$ & $0,34 \pm 0,05$ & $0,03 \pm 0,0$ & $0,16 \pm 0,02$ & $0,08 \pm 0,01$ & $0,04 \pm 0,01$ & $0,04 \pm 0,01$ & $12,48 \pm 1,72$ \\
\hline \multicolumn{2}{|c|}{$\begin{array}{l}\text { Total em } 2005 \mathrm{~kg} \\
\text { ha }^{-1} \mathrm{ano}^{-1}\end{array}$} & 1,82 & 0,14 & 0,86 & 0,50 & 0,25 & 0,13 & 32,34 \\
\hline \multirow[t]{2}{*}{2} & A & $13,09 \pm 0,85$ & $1,01 \pm 0,07$ & $6,18 \pm 0,40$ & $3,70 \pm 0,24$ & $1,86 \pm 0,12$ & $0,8 \pm 0,05$ & $175,75 \pm 11,41$ \\
\hline & B & $3,60 \pm 0,59$ & $0,28 \pm 0,04$ & $1,70 \pm 0,28$ & $0,86 \pm 0,14$ & $0,40 \pm 0,07$ & $0,44 \pm 0,07$ & $131,73 \pm 21,52$ \\
\hline \multirow[t]{2}{*}{3} & A & $11,87 \pm 1,45$ & $0,92 \pm 0,11$ & $5,60 \pm 0,68$ & $3,36 \pm 0,41$ & $1,69 \pm 0,21$ & $0,73 \pm 0,09$ & $159,27 \pm 19,43$ \\
\hline & B & $3,44 \pm 0,45$ & $0,26 \pm 0,03$ & $1,63 \pm 0,21$ & $0,82 \pm 0,11$ & $0,39 \pm 0,05$ & $0,42 \pm 0,05$ & $126,13 \pm 16,36$ \\
\hline \multirow[t]{2}{*}{4} & A & $19,64 \pm 1,92$ & $1,52 \pm 0,15$ & $9,28 \pm 0,91$ & $5,56 \pm 0,54$ & $2,80 \pm 0,27$ & $1,20 \pm 0,12$ & $263,63 \pm 25,77$ \\
\hline & B & $4,94 \pm 0,71$ & $0,38 \pm 0,05$ & $2,33 \pm 0,33$ & $1,18 \pm 0,17$ & $0,56 \pm 0,08$ & $0,61 \pm 0,09$ & $180,81 \pm 25,83$ \\
\hline \multicolumn{2}{|c|}{$\begin{array}{l}\text { Total em 2006k } \\
\text { ha }^{-1} \mathrm{ano}^{-1}\end{array}$} & 56,58 & 4,37 & 26,72 & 15,48 & 7,70 & 4,2 & 1037,32 \\
\hline \multirow[t]{2}{*}{5} & A & $34,37 \pm 5,0$ & $2,65 \pm 0,39$ & $16,23 \pm 2,36$ & $9,72 \pm 1,42$ & $4,89 \pm 0,71$ & $2,10 \pm 0,31$ & $461,35 \pm 67,17$ \\
\hline & B & $7,45 \pm 1,49$ & $0,57 \pm 0,11$ & $3,52 \pm 0,70$ & $1,78 \pm 0,36$ & $0,84 \pm 0,17$ & $0,91 \pm 0,18$ & $272,93 \pm 54,67$ \\
\hline \multirow[t]{2}{*}{6} & A & $14,76 \pm 2,71$ & $1,14 \pm 0,21$ & $6,97 \pm 1,28$ & $4,18 \pm 0,77$ & $2,10 \pm 0,39$ & $0,90 \pm 0,17$ & $198,14 \pm 36,33$ \\
\hline & B & $3,62 \pm 0,35$ & $0,28 \pm 0,03$ & $1,71 \pm 0,17$ & $0,86 \pm 0,08$ & $0,41 \pm 0,04$ & $0,44 \pm 0,04$ & $132,59 \pm 12,91$ \\
\hline \multirow[t]{2}{*}{7} & A & $15,64 \pm 2,20$ & $1,21 \pm 0,17$ & $7,39 \pm 1,04$ & $4,42 \pm 0,62$ & $2,23 \pm 0,31$ & $0,96 \pm 0,13$ & $209,97 \pm 29,57$ \\
\hline & B & $4,57 \pm 0,56$ & $0,35 \pm 0,04$ & $2,16 \pm 0,27$ & $1,09 \pm 0,13$ & $0,51 \pm 0,06$ & $0,56 \pm 0,07$ & $167,46 \pm 20,66$ \\
\hline \multicolumn{2}{|c|}{$\begin{array}{l}\text { Total em } 2007 \mathrm{~kg} \\
\text { ha }^{-1} \mathrm{ano}^{-1}\end{array}$} & 80,42 & 6,2 & 37,98 & 22,05 & 10,98 & 5,88 & 1442,44 \\
\hline
\end{tabular}

*A: Ramo tenro e folhas.** B: Ramo lignificado.Intervalo de confiança para média, a 95\% ( $\mathrm{n}=6)$.

Considerando apenas o N, P, K, a adição da fitomassa podada da parte aérea da gliricídia, em 2006, proporcionou, respectivamente, uma adição ao solo de cerca de 56, 4,4 e $27 \mathrm{~kg} \mathrm{ha}^{-1}$ e cerca de 80, 6,2 e $38 \mathrm{~kg} \mathrm{ha}^{-1}$ em 2007. Este incremento está relacionado à maior produção de fitomassa em 2007. Esses resultados são semelhantes aos obtidos por Queiroz et al. (2007), que relataram uma adição de $\mathrm{N}, \mathrm{P}, \mathrm{K}$ ao solo com podas da gliricídia de cerca de 75, 4,1 e $29 \mathrm{~kg} \mathrm{ha}^{-1} \mathrm{ano}^{-1}$, respectivamente, obtidos em duas podas anuais de ramos com diâmetro de até $1,5 \mathrm{~cm}$ e de folhas, e sem que o sistema de aleias, no espaçamento de 5,6 x 0,5 m, tenha recebido adubação na ocasião de plantio.

Queiroz et al. (2007) observaram que a quantidade de $\mathrm{N}$ acumulada em duas podas em 2006, com e sem adubação fosfatada, foi em torno de $90 \mathrm{~kg} \mathrm{ha}^{-1} \mathrm{ano}^{-1} \mathrm{e}$ $75 \mathrm{~kg} \mathrm{ha}^{-1} \mathrm{ano}^{-1}$, respectivamente. Comparando esses resultados com os deste trabalho, verifica-se que, em 2007, a quantidade de $\mathrm{N}$ adicionada ao sistema, $80,42 \mathrm{~kg} \mathrm{ha}^{-1} \mathrm{ano}^{-1}$, foi intermediária àquelas obtidas pelo autor, mesmo tendo aplicado apenas $5 \mathrm{~L}$ de composto orgânico na ocasião de plantio.
Sabendo-se que, em cultivos orgânicos, não é permitida a aplicação de adubos químicos sintéticos, a adição de $\mathrm{N}, \mathrm{P}, \mathrm{K}$ ao sistema pelas podas aplicadas em 2006 e 2007 (Tabela 3), equivale, respectivamente, a uma adubação nitrogenada com as aplicações de 129 e $183 \mathrm{~kg} \mathrm{ha}^{-1}$ de ureia, a uma adubação fosfatada com 56 e $79 \mathrm{~kg} \mathrm{ha}^{-1}$ de superfosfato simples e a uma adubação potássica com 55 e $79 \mathrm{~kg} \mathrm{ha}^{-1}$ de cloreto de potássio. Salienta-se que este resultado foi obtido com baixa adição de insumos externos para o estabelecimento e a manutenção do cultivo em aleias de gliricídia.

Com relação a Ca, $\mathrm{Mg}$ e S depositados no solo derivados da poda da gliricídia em 2006, as quantidades destes nutrientes foram em torno de $15,5 \mathrm{~kg} \mathrm{ha}^{-1}$ de Ca, 7,7 kg ha-1 de Mg e 4,2 kg ha-1 de S, e em 2007, foram em torno de $22 \mathrm{~kg} \mathrm{ha}^{-1}$ de Ca, $11 \mathrm{~kg} \mathrm{ha}^{-1} \mathrm{de} \mathrm{Mg}$ e $6 \mathrm{~kg} \mathrm{ha}^{-1}$ de $\mathrm{S}$ (Tabela 3 ).

Na Costa Rica, Henriksen et al. (2002) avaliaram o cultivo em aleias de gliricídia, consorciada com milho e feijão. Verificaram que, mesmo depois de sete anos, a fitomassa seca acumulada anualmente era de 5,7 t ha" ${ }^{1}$ ano" ${ }^{1}$, proporcionando uma aplicação 
equivalente a 106 kg ha" ${ }^{1}$ ano"1 de N e 8,3 kg ha"1 ano"1 de $\mathrm{P}$ pela gliricídia. Esses resultados foram cerca de $32 \%$ e $34 \%$ acima do obtido neste trabalho para $\mathrm{N}$ e $\mathrm{P}$, em 2007, que foi 80,42 e 6,3 kg ha"1 ano"1 de $\mathrm{N}$ e $\mathrm{P}$, respectivamente.

Outro fator importante proporcionado pela poda das gliricídias é a cobertura do solo sob a área de copa das frutíferas com a fitomassa podada. Apesar de não ter sido medida, pôde-se observar que, em torno da área de copa, houve conservação da umidade do solo por um período longo e menor infestação por vegetação espontânea em relação às plantas que não receberam a adubação verde. Tudo isso, provavelmente, também favoreceu a fauna do solo. O manejo de deixar o material de poda das plantas ou restos de cultura sobre a superfície do solo, ao invés de enterrá-la, pode, além de prolongar o efeito da matéria orgânica no solo, diminuir a oscilação da temperatura do solo, a infestação de plantas espontâneas e a perda de umidade por evaporação (FARIA, 2004; OLIVEIRA et al., 2006).

As adubações verdes com ramos tenros com folhas, proporcionadas pelas diversas podas da gliricídia, nos anos de 2006 e 2007 (Tabela 3), contribuíram com boa parte da nutrição das frutíferas, considerando a quantidade de N, P, K recomendada para a adubação de ambas, referentes ao terceiro e quarto anos (Tabela 4).
Ao relacionar o manejo de podas das árvores, concentrado no período chuvoso (meses de novembro a abril) com a quantidade de N, P e K adicionadas ao sistema (Tabelas 1 e 3), e as épocas mais adequadas para o manejo da adubação de cada frutífera (Tabela 4), pode-se inferir que o intervalo e a época das podas estavam conformes a algumas recomendações para a adubação das frutíferas, em especial a da gravioleira.

A contribuição do adubo verde no fornecimento de N, tanto em 2006 quanto 2007, foi superior à recomendação de ambas as frutíferas (Tabelas 3 e 4). Por outro lado, as quantidades de P e K recomendadas pelas frutíferas são superiores àquelas proporcionadas pelas adubações verdes, exceto para o K na adubação da mangueira no quarto ano pós-plantio.

De acordo com as recomendações de adubação da mangueira (Tabela 4), no terceiro e no quarto ano pós-plantio, as contribuições da adubação verde variaram de 37 a 45\% do P exigido pela cultura. A contribuição das gliricídias com relação ao K foi de 54 \% do recomendado na adubação do terceiro ano pós-plantio e de $17 \%$ acima do exigido na adubação do quarto ano pós-plantio.

Tabela 4 - Quantidade de N, P e K recomendada para adubação da mangueira e da gravioleira (156 plantas ha-1). Table 4 - Levels of N, P and K recommended for mango and soursop trees fertilization (156 plants ha ${ }^{-1}$ ).

\begin{tabular}{|c|c|c|c|c|}
\hline \multirow{3}{*}{ Época de adubação } & \multicolumn{3}{|c|}{ Quantidade recomendada para a mangueira ${ }^{1}$} & \multirow[b]{2}{*}{$\mathrm{K}$} \\
\hline & Parcelamento & $\mathrm{N}$ & $\mathrm{P}$ & \\
\hline & \multicolumn{3}{|c|}{$\mathrm{kg} \mathrm{ha}^{-1}$} & \\
\hline \multirow[t]{3}{*}{$3^{0}$ ano pós-plantio } & Outubro & 10,92 & & 13,00 \\
\hline & Janeiro & 10,92 & 9,50 & 13,00 \\
\hline & Março & 9,36 & & 13,00 \\
\hline Total & & 31,20 & 9,50 & 39,00 \\
\hline \multirow[t]{3}{*}{$4^{0}$ ano pós-plantio } & Antes da floração (inverno) & 3,12 & & 2,60 \\
\hline & Após o pegamento do fruto & 12,48 & 11,00 & 10,40 \\
\hline & Após a colheita & 15,60 & & 13,00 \\
\hline \multirow[t]{2}{*}{ Total } & & 31,20 & 11,00 & 26,00 \\
\hline & Quantidade reco & graviol & & \\
\hline \multirow[t]{2}{*}{$3^{0}$ ano pós-plantio } & Início do período chuvoso & 15,60 & 10,25 & 19,50 \\
\hline & Final do período chuvoso & 15,60 & 10,25 & 19,50 \\
\hline Total & & 31,20 & 20,50 & 39,00 \\
\hline \multirow[t]{3}{*}{$3^{0}$ ano pós-plantio } & Início do período chuvoso & 20,25 & 13,33 & 25,33 \\
\hline & Meio do período chuvoso & 20,25 & 13,33 & 25,33 \\
\hline & Final do período chuvoso & 20,30 & 13,34 & 25,34 \\
\hline Total & & 60,80 & 40,00 & 76,00 \\
\hline
\end{tabular}

${ }^{1}$ Fonte: Baseada na recomendação de MAGALHÃES; BORGES, $2000 .{ }^{2}$ Fonte: Baseada na recomendação de MANICA, 1994.

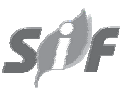

Revista Árvore, Viçosa-MG, v.35, n.4, p.781-789, 2011 
Ao relacionar as épocas de podas com as épocas recomendadas para a adubação da mangueira, pode-se inferir que a adubação verde não contribuiu efetivamente para a adubação da mangueira, especialmente à do quarto ano, isto porque as adubações verdes ocorreram após as épocas recomendadas, exceto na ocasião de pós-colheita. Nesta ocasião, a adubação verde de janeiro e abril, provavelmente, beneficiou a mangueira.

Com relação ao recomendado para a gravioleira (Tabela 4), a contribuição da adubação verde no fornecimento de $\mathrm{P}$ e K foi menor na adubação do quarto ano pós-plantio em relação à do terceiro ano, passando de 17 para $12,5 \%$ do $\mathrm{P}$ e 54 para $40 \%$ do K recomendados. Observa-se que a exigência no quarto ano pós-plantio foi quase o dobro da do terceiro ano. A adubação verde contribuiu muito pouco no fornecimento de P para a gravioleira. Segundo Pinto et al (2001), esta frutífera é muito exigente em $\mathrm{P}$ e $\mathrm{K}$, devendo, portanto, haver outra fonte de adubação, principalmente fosfatada.

Ao relacionar as épocas de podas com as épocas recomendadas para a adubação da gravioleira, pode-se inferir que as adubações verdes de 2006 e 2007 contribuíram de modo mais significativo para esta frutífera, porque as épocas de poda estavam de acordo com recomendações para a sua adubação.

O fornecimento de $\mathrm{N}$ anual através da adubação verde chegou a ser de $43 \%$ e $108 \%$ acima do recomendado para a mangueira e de $43 \%$ e $5 \%$ acima do recomendado para a gravioleira, nas adubações do terceiro e quarto anos pós-plantio, respectivamente.

Deve-se salientar a necessidade e a importância de mais avaliações ao longo do tempo para verificar a sustentabilidade produtiva e econômica deste consórcio, pois, em geral, de acordo com Rodrigues et al. (2007), o que se espera de um sistema de produção é a otimização do uso dos fatores de produção, com redução de custos, gerando, consequentemente, maior renda para o produtor.

\section{CONCLUSÕES}

A gliricídia no sistema de aleias desenvolveu-se bem no pomar orgânico de mangueira e gravioleira, apresentando elevada sobrevivência (93\%), boa produção de fitomassa seca e adição de nutriente, com potencial de uso contínuo no sistema.

Revista Árvore, Viçosa-MG, v.35, n.4, p.781-789, 2011
O crescimento e o desenvolvimento da gliricídia permitiram que o regime de poda se adequasse às épocas recomendadas para as adubações das frutíferas, em especial a gravioleira.

A quantidade de fitomassa seca e de nutrientes adicionados ao sistema, em três podas anuais da gliricídia, foi maior no segundo ano de manejo das podas.

A quantidade de $\mathrm{N}$ adicionada ao sistema foi maior que a adubação recomendada para a mangueira e a gravioleira, enquanto as quantidades de P e K não foram suficientes para suprir o recomendado para as duas frutíferas.

A adubação verde com gliricídia, no manejo adotado, contribuiu de forma mais significativa na nutrição da gravioleira.

\section{AGRADECIMENTOS}

À Universidade Estadual do Norte Fluminense e à Faperj, pelo apoio financeiro. À Embrapa Agrobiologia, pelo fornecimento das estacas de gliricídia. À Respa Indústria e Comércio, pelo apoio logístico.

\section{REFERÊNCIAS}

ANDERSON, J. D.; INGRAM, J. S. I. Tropical soil biology and fertility: a handbook of methods. 2.ed. Wallingford: UK CAB International, 1996. 171p.

BARRETO, A. C.; FERNANDES, M. F. Cultivo de Gliricidia sepium e Leucaena leucocephala em alamedas visando a melhoria dos solos dos tabuleiros costeiros. Pesquisa Agropecuária Brasileira, v.36, n.10, p.1287-1293, 2001.

BARRETO, A. C.; FERNANDES, M. F.; CARVALHO FILHO, O. M. Cultivo de alamedas de gliricídia (Gliricidia sepium) em solos dos tabuleiros costeiros. 2004. 4p. (Circular Técnica, 36)

BRAGA, J. M.; DEFELIPO, B. V. Determinação de espectrofotométrica de fósforo em extratos de solo e material vegetal. Revista Ceres, v.21, n.113, p.73-85, 1974.

COCHRAN, W. G. Técnicas de

amostragem. Rio de Janeiro: Fundo de Cultura, 1955. 555p. 
CORRÊA, F. L. O. et al. Produção de serapilheira em sistema agroflorestal multiestratificado no Estado de Rondônia, Brasil. Ciência e Agrotecnologia, v.30, n.6, p.1099-1105, 2006.

COSTA, G. S. et al. Manejo do solo para produção orgânica de gravioleira e mangueira no Norte Fluminense. In: CONGRESSO BRASILEIRO DE FRUTICULTURA, 18., 2004, Florianópolis. 2004. Anais... Florianópolis: 2004a. CD ROM.

COSTA, G. S. et al. Desempenho de leguminosas arbóreas na formação de aléias em um sistema agroflorestal na região Norte Fluminense. In: FERTBIO - Lages - SC, 2004. Anais... Lages: 2004a. CD-ROM.

FARIA, C. M. B. Comportamento de leguminosas para adubação verde no Submédio São Francisco. Petrolina: Embrapa Semi-Árido, 2004. 22 p. (Boletim de Pesquisa e Desenvolvimento, 63)

FERRAZ JÚNIOR, A. S. L. Cultivo em aléias como alternativa para a produção de alimentos na agricultura faliar do tropico úmido. In: MOURA, E. G. (Org.) Agroambientes de transição: entre o trópico úmido e o semi-arido Maranhense - Atributos, alterações, uso da produção familiar. São Luiz: UEMA-MA, 2002. p.61-88. Disponível em: <www.iica.org.br/docs/publicacoes/ publicacoes $>$ - Acesso em: 03/02/2008)

HENRIKSEN, I.; MICHELSEN, A.; SCHLÖNVOIGT, A. Tree species selection and soil tillage in alley cropping systems with Phaseolus vulgaris L. in a humid premontane climate: biomass production, nutrient cycling and crop responses. Plant and Soil, v.240, p.145-159, 2002.

KANG, B. T. Alley cropping - soil productivity and nutrient recycling. Forest Ecology e Management, v.91, p.75-82, 1997.

MAFRA, A. L. et al. Adição de nutrientes ao solo em sistemas agroflorestais do tipo "cultivo em aléias” e em cerrado na região de Botucatu, SP. Scientia Forestalis, n.54, p.41-54, 1998.
MAGALHÃES, A. F. J.; BORGES, A. L. Calagem e adubação. In: MATOS, A. P. (Org). Manga: produção - Aspectos técnicos. Cruz das Almas: Embrapa Mandioca e Fruticultura, 2000. p.35-44, (Comunicação para Transferência de Tecnologia).

MALAVOLTA, E.; VITTI, G. C.; OLIVEIRA, S. A. Avaliação do estado nutricional de plantas, princípio e adaptações. 2.ed. Piracicaba: Potafo, 1997. 319p.

MANICA, I. Fruticultura - Cultivo das anonáceas: ata, cherimólia e graviola. Porto Alegre: Evangraf, 1994. 117p.

OLIVEIRA, F. L. et al. Crescimento e produtividade do inhame cultivado entre faixas de guandu em sistema orgânico. Horticultura Brasileira, v.24, n.1, p.53-58, 2006.

PINTO, A. C. Q. et al. Tratos culturais. In: OLIVEIRA, M. A. S. (Ed). Graviola: produção - Aspectos técnicos. Planaltina: Embrapa Cerrados, 2001. p.26-33. (Embrapa Informação Tecnológica).

QUEIROZ, L. R. et al. Avaliação da produtividade de fitomassa e acúmulo de N,P,K em leguminosas arbóreas no sistema de aléias, em Campos dos Goytacazes-RJ. Revista Árvore, v.31, n.3, p.38-390, 2007.

RODRIGUES, E. R. et al. Avaliação econômica de sistemas agroflorestais implantados para recuperação de reserva legal no Pontal do Paranapanema, São Paulo. Revista Árvore, v.31, n.5, p.941-948, 2007.

SILVA, G. T. A. et al. Correlação entre a composição química e a velocidade de decomposição e liberação de nitrogênio de folhas de dez espécies em um sistema agroflorestal. In: CONGRESSO BRASILEIRO DE SISTEMAS AGROFLORESTAIS, 6., 2006, Campos do Goytacazes. Anais... Campos do Goytacazes: UENF, 2006. CD ROM. 